\title{
\$6bn package to cut US carbon emissions comes under attack
}

[WASHINGTON] Energy policy experts are sharply divided about the adequacy of a proposed research and tax incentive package, worth $\$ 6.3$ billion over five years, that the Clinton administration says is needed for the United States to comply with the Kyoto agreement on climate change.

The package - part of the budget proposals announced last week - has been welcomed by supporters of the Kyoto deal. It is the administration's first action to comply with the agreement, and may be its only action in advance of the agreement's ratification by the US Senate.

But economists, including those at the Energy Information Administration (EIA), an independent branch of the government charged with assessing such matters, doubt whether the package will have much impact on total US emissions of carbon dioxide. According to the EIA, these will exceed their 1990 levels by 34 per cent by 2010; the Kyoto accord requires emissions reductions of 7 per cent by then.

At a hearing today (12 February) of the Science Committee of the House of Representatives, chaired by James Sensenbrenner

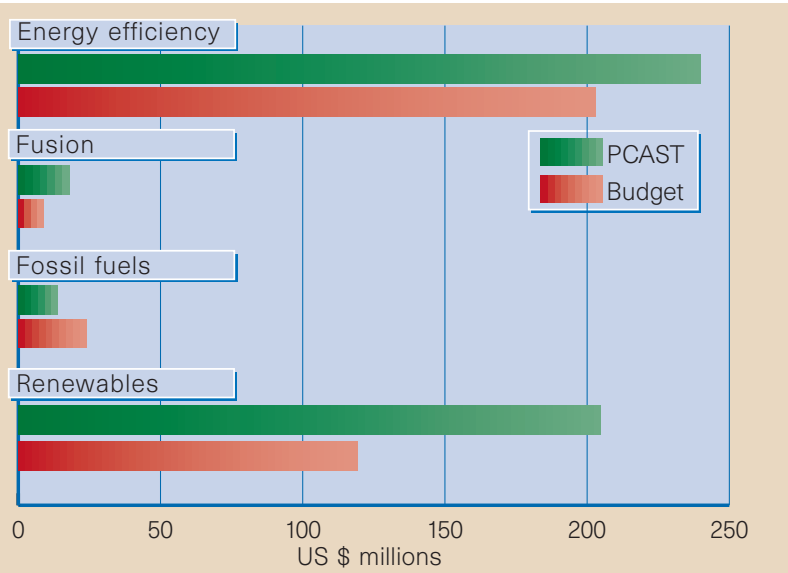

Two views: contrasting increases proposed between 1997 and 1999 for applied energy research by the President's Council of Advisors on Science and Technology, and in the Clinton administration's 1999 budget request.
(Republican, Wisconsin), Republicans may launch an attack on the package that could further diminish its impact.

The package consists of $\$ 3.7$ billion of tax incentives for businesses and consumers, and $\$ 2.7$ billion of spending on research and development of technologies to cut carbon emissions, over the period 1999-2003.

The tax incentives include credits of $\$ 3,000$ for individuals buying big cars that use less fuel - there will be no incentive to

\section{Clues to the origins of canyons on Mars}

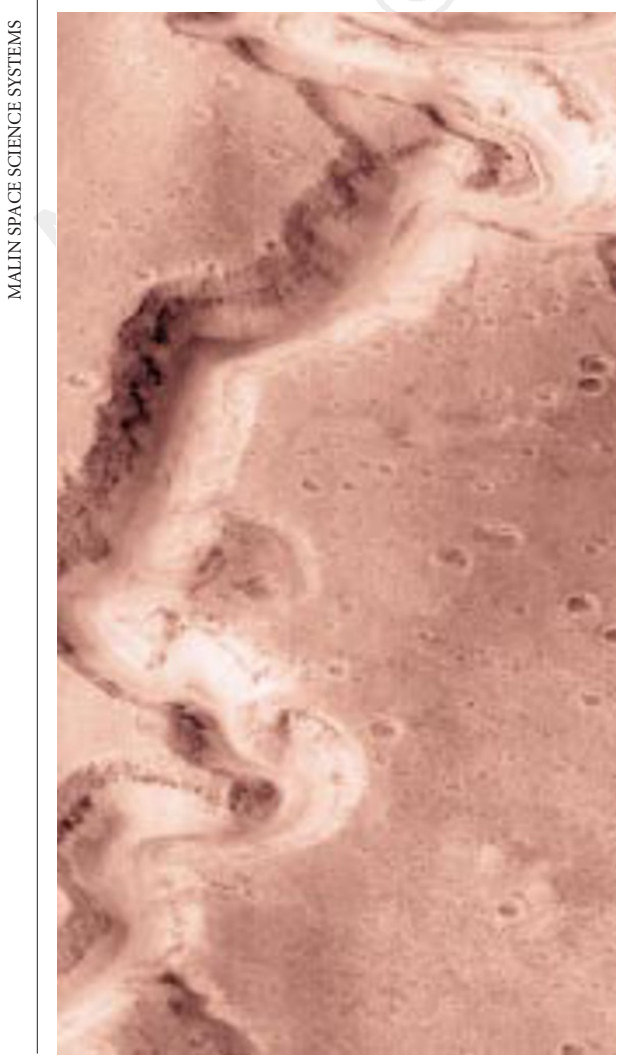

[WASHINGTON] Mystery veils the origin of the $2.5-\mathrm{km}$-wide canyon of Nanedi Vallis, one of the Martian valley systems - here pictured by the Mars Orbiter Camera. The picture was taken last month during the 87th orbit of the Mars Global Surveyor spacecraft.

Rocky outcrops occur along the upper walls, and weathered debris is found on the lower slopes and along the floor of the canyon, which cuts through cratered plains in the Xanthe Terra region of Mars.

Some features, such as terraces within the canyon and the 200-metre wide channel - both evident near the top of the picture - suggest it arose from continual fluid flow. Others, such as the lack of a contributing pattern of smaller channels on the surface surrounding the canyon, the shape of tributaries and the size and tightness of the apparent meanders, indicate that it was formed by collapse.

It is now thought likely that both continual flow and collapse were responsible for the canyon's appearance. Further observations are now planned to help to distinguish the relative effect of these and other potential formation and modification processes.

buy smaller vehicles, says the administration — and a batch of similar credits for everything from solar roof panels to full-blown combined heat and power systems.

The research and development proposals are broadly based on recommendations made last November by a panel of the President's Council of Advisors on Science and Technology, chaired by John Holdren of the John F. Kennedy School of Government at Harvard University. Its report called for extra investment in energy supply research at the Department of Energy (DOE) of \$370 million this year, rising to $\$ 1$ billion by 2003 .

It is difficult to compare what Holdren asked for with what the budget delivers. The report based its recommended increases on a level of spending for 1998 that was subsequently cut by the Congress. For example, Holdren suggested that research in solar and renewable energy be increased next year by $\$ 130$ million, to $\$ 475$ million. The Clinton budget does ask for a substantial increase, of $\$ 90$ million. But, because the baseline has been cut back, the Clinton proposal increases spending to just $\$ 390$ million. In other words, the budget proposal goes halfway to meeting the Holdren panel's expectations.

Overall, the Holdren report envisaged extra spending of $\$ 3.8$ billion at DOE over the five years from 1999 to 2003 . The Clinton budget proposes extra expenditure of $\$ 1.9$ billion at the department over the period - again, half what the report asked for. The rest of the $\$ 2.7$ billion research and development package proposed by Clinton is spent in other agencies, chiefly the Environmental Protection Agency (EPA).

A spokesman for the EPA was unable to provide a detailed breakdown of this expenditure. But briefings to Congress indicate that the extra funds will go to technology partnership programmes between the 
agency and industry. Such programmes have, in the past, been strongly resisted by Republicans in the Congress.

If the package is implemented, spending on energy supply research and development will still be at historically low levels. This investment peaked at almost $\$ 10$ billion, in today's money, in 1978.

The Holdren report sought to lift it from a 1997 trough of just \$1.3 billion. Mike Doyle (Democrat, Pennsylvania), a member of the science committee and supporter of coal research, says: " $\$ 2.7$ billion [over five years] is a pittance. We should be spending maybe ten times as much if we're serious about this."

Testifying before the science committee last week, Jay Hakes, administrator of the EIA, said that the long life of cars, buildings and factories ensured that there were "no quick fixes" to reducing emissions.

EIA already assumes improvements in energy efficiency in its projections, he said, adding that changes in those assumptions resulting from new technology "don't come close" to stabilizing US carbon emissions. "It's unlikely that any reduction can be achieved without a price mechanism," he said.

Government officials argue that the new energy research effort is more focused than before. They say the old programmes involved large and unproductive 'technology demonstrators'. The new programmes such as a Nuclear Energy Research Initiative, recommended by Holdren - allow universities and government laboratories to compete for funds under carefully supervised peer review.

But environmentalists have nevertheless declared war on the new nuclear initiative. And according to congressional staff — even liberal Democrats - the DOE programme contains items that look more like industry support than peer-reviewed research.

As the proposal passes through Congress, its fate will depend on the wider budget picture and on Republican sentiment towards Kyoto. At last week's science committee hearing, some Republicans expressed support for energy research. Roscoe Bartlett (Republican, Maryland) said he did not believe in manmade global warming, but still wanted research on alternatives because they are needed to replace fossil fuels.

Alden Meyer, a lobbyist for the Union of Concerned Scientists, which supports strong action to reduce emissions, hopes and believes that the administration will fight hard to keep the package in the budget. "The question is whether the Republicans will oppose it, as a proxy vote against the Kyoto deal, or support it as something in line with their view that a carrot, and not a stick, should be used" to cut emissions, said Meyer. "I think they are split, currently." But, even if the package prevails, there is little evidence that it will help the United States to comply with its Kyoto target.

Colin Macilwain

\section{Physicists oppose plan to slim down fusion reactor..}

[MUNICH] European fusion scientists are determined to stick to the original ambitions of the 'next-step' fusion reactor, ITER, despite growing concern that the United States may back away, and waning enthusiasm from some European countries.

ITER (International Thermonuclear Experimental Reactor) is a collaborative project between Europe, Japan, Russia and the United States. As currently planned, it would allow scientists to study the physics of a burning plasma, as well as engineering problems, such as the effect of extreme neutron bombardment on the reactor vessel walls. Results would feed into the design of a future power generating fusion reactor.

The costs, estimated to total US $\$ 10$ billion, would be shared about equally between the partners. But the collaboration is under serious strain. Earlier this month, the US Department of Energy suggested cutting its budget for ITER by three-quarters, saying it wanted to divert the money to its domestic fusion research programme (see Nature 391, 522; 1998). It has already sliced one-third off its budget for magnetic fusion since 1995 .

European scientists have not so far been subject to such swingeing cuts. But they are aware that political enthusiasm is fragile.

Strained budgets have slowed the project's pace. Scientists accept that they will not be moving to the planned construction phase when the engineering design agreement (EDA) phase ends in July. The best they can hope is for a three-year extension to the EDA.

If the EDA is extended - which requires the agreement of all parties by July - a working group will be set up to propose cheaper options for the ITER machine. Although all partners agree that this is a good idea, they do not agree on which technical and scientific objectives could in principle be dropped.

Many US scientists now favour a more limited project that would abandon most of ITER's engineering aims, focusing instead on a purely plasma-physics programme.
That could imply a much smaller reactor whose ambitions would be confined to plasma ignition rather than sustained burn.

Most European fusion physicists are deeply opposed to such an idea, and the European Commission intends to fight to maintain an international fusion programme orientated towards the goal of a fusion energy generator. "We would not settle for a programme dissociated from energy considerations," says Klaus Pinkau, director of the Max Planck Institute for Plasma Physics in Garching, Germany.

ITER decisions are made by consensus, so a major battle between the partners seems likely. The signs in Europe are that the commission will get backing for an extension of the EDA, provided cheaper options are investigated. John Battle and Jürgen Rüttgers, the research ministers of Britain and Germany - the two European countries with the largest national fusion programmes - have expressed waning personal enthusiasm for ITER, but neither is so far pressing for the idea to be abandoned.

The extent to which European Union (EU) research ministers may be prepared to wager on fusion power solving long-term energy problems may become clearer after their meeting this week to discuss the union's fifth Framework programme of research, set to run from 1998 to 2002. Fusion research is a significant part of the programme.

Extending the EDA and maintaining national fusion programmes, nearly half of whose costs are met by the EU, would, according to the commission, require an inflation-linked continuation of the current Framework budget — ECU920 million (US\$1,013 million) over the five years. Most member states want to gamble less than this, and the EU's British presidency is aiming for a consensus between ECU770 million and ECU850 million. That would mean a drop in fusion research funding, but would not threaten an EDA extension.

Alison Abbott

\section{...while project wins backing in Canada}

[MUNICH] A Canadian

consortium, ITER Canada,

has been set up to promote Canada's participation in the International Thermonuclear Experimental Reactor (see above), and to push for a Canadian site to be chosen for the reactor if and when it is built. Canada's involvement is channelled through the
European partnership.

The utilities company Hydro Ontario has provided C\$6 million (US\$4 million) over the next three years, and other companies, banks and trade unions have guaranteed $\mathrm{C} \$ 3$ million. A further $\mathrm{C} \$ 2$ million is being sought from the federal government and the governments of Quebec and

Ontario where the two potential ITER sites are located.

"If the governments do not come in, we will have to scale down our efforts," says Peter Barnard, chairman of ITER Canada. Apart from Canada, only Japan and Italy are still offering sites. 